\title{
Rapid diversification of the Australian Amitermes group during late Cenozoic climate change
}

\section{Authors}

Bastian Heimburger ${ }^{1 *}$, Leonie Schardt ${ }^{12}$, Alexander Brandt ${ }^{13}$, Stefan Scheu ${ }^{14}$, Tamara R. Hartke ${ }^{1}$

\section{Affiliations}

1J.F. Blumenbach Institute of Zoology and Anthropology, University of Göttingen, Untere Karspüle 2, 37073 Göttingen, Germany

${ }^{2}$ Current address: Functional Environmental Genomics, Translational Biodiversity Genomics (LOEWE-TGB), Senckenberg Nature Research Society, Senckenberganlage 25, 60325 Frankfurt, Germany

${ }^{3}$ Current address: Department of Ecology and Evolution, University of Lausanne, UNIL Sorge, Le Biophore, $\mathrm{CH}-1015$, Lausanne, Switzerland

${ }^{4}$ Centre of Biodiversity and Sustainable Land Use, Büsgenweg 1, 37077 Göttingen, Germany

\section{Corresponding author}

Bastian Heimburger

J.F. Blumenbach Institute of Zoology and Anthropology

University of Göttingen

Untere Karspüle 2

37073 Göttingen

Germany

Email: bastian.heimburger@biologie.uni-goettingen.de 


\section{Abstract}

Late Cenozoic climate change led to the progressive aridification of Australia over the past 15 million years. This gradual biome turnover fundamentally changed Australia's ecosystems, opening new niches and prompting diversification of plants and animals. One example is the Australian Amitermes Group (AAG), consisting of the Australian Amitermes and affiliated genera. Although it represents the most speciose and diverse higher termite group in Australia, little is known about its evolutionary history. We used ancestral range reconstruction and diversification analyses to illuminate 1) the origin and phylogenetic relationships of the $A A G, 2$ ) biogeographical processes leading to the current continent-wide distribution, and 3) timing and pattern of diversification in the context of late Cenozoic climate change. By estimating the first time-calibrated phylogeny, we show that the AAG is a monophyletic group, whose ancestor arrived 11-10 million years ago from Southeast Asia. Ancestral range reconstruction indicates that Australia's monsoon region was the launching point for a continental radiation that has been shaped by range expansions and within-area speciation rather than vicariance. We found that multiple arid species diversified from mesic and tropical ancestors in the Plio-Pleistocene, but also observed diversification in the opposite direction. Finally, we show that two pulses of rapid diversification coincided with past climate change during the late Miocene and early Pliocene. Consistent with rapid diversification, species accumulation slowed, likely caused by progressive niche saturation. This study provides a stepping stone for predicting the future response of Australia's termite fauna in the face of human-mediated climate change. 


\section{Introduction}

Australia demonstrates evolutionary challenges that changing climate can pose to organisms and ecosystems. Starting in the late Miocene roughly 10 million years ago (Mya), Australia's previously warm and wet climate became cool and dry, a period of regional climatic instability known as the "Hill Gap" (Hill, 1994). The widespread rainforests retreated to local refugia (Yeates et al., 2002; Cassis et al., 2017), while climatic oscillations of the Pliocene and Pleistocene further shaped the present-day arid and semi-arid zones (Byrne et al., 2008). Despite its relatively young age, the Australian arid biome has a rich and unique flora and fauna (Raven \& Yeates, 2007; Guzik et al., 2011; Powney et al., 2010; Ladiges et al., 2011; Andersen, 2016), suggesting either the persistence of ancient lineages or (rapid) radiations in parallel with the increasing aridification of the continent (Crisp et al., 2004; Byrne et al., 2008). Thus, Australia's extraordinary biodiversity has not only been shaped by relictualism stemming from the breakup of Gondwana (Barrett \& Williams, 1998; Barden \& Ware, 2017), but also by vicariance, in situ speciation, and phylogeographic structuring of populations in response to local environmental conditions (reviewed in Cassis et al., 2017).

Today, Australia's arid zone covers roughly $70 \%$ of the continent and separates the once predominant mesic biome into eastern and south-western mesic zones (Byrne et al., 2008). The mesic biome includes i.a. the last remnants of rainforest in Australia and is characterized by high levels of rainfall during the winter season (Byrne et al., 2011). Despite receiving similar total amounts of rainfall, the monsoonal tropics in northern Australia are distinguished by summer rainfall, cyclones, and a dry winter season (Bowman et al., 2010). While the flora and fauna of each major biome has been extensively studied (Pepper et al., 2011; Cardillo et al., 2017; Harms et al., 2019; reviewed in Byrne et al., 2008; 2011; Bowman et al., 2010; Rix et al., 2015), only a handful of studies have addressed patterns of diversification between Australian biomes at a continent-wide scale (Fujita et al., 2010; Owen et al., 2017; Brennan \& Keogh, 2018), and none so far on Australia's rich termite fauna (Calaby \& Gay, 1959).

Here, we examine the diversification of Amitermes Silvestri and allied genera (Ahamitermes, Drepanotermes, Incolitermes, and Invasitermes), which we refer to as the Australian Amitermes Group (AAG). The AAG forms the most diverse and speciose group of higher termites (Termitidae) in Australia, including about 100 described species (Krishna et al., 2013), many of which play important roles in ecosystem functioning across the continent (Coventry et al., 1988; Noble et al., 2009, Evans et al., 2011). The AAG and other termite lineages are thought to have arrived in Australia relatively recently, 11 to 13 Mya 
(Bourguignon et al., 2017) suggesting that they initially diversified as more or less warm/wet conditions terminated in the late Miocene before facing the challenge of rapidly intensifying aridification in the Plio-Pleistocene. Indeed, diversification in other Australian animal and plant groups coincides with the increase in aridity and the expansion of the arid zone in the last 10 million years (Byrne et al., 2008; 2018), including Australian Coptotermes and Nasutitermitinae (Lee et al., 2015; Arab et al., 2017).

AAG species occur across the continent, are adapted to temperate, (sub)tropical, and arid climates, and have persisted in times of severe climate change (Abensperg-Traun \& Steven, 1997). This makes them a model system to examine the effects of Australia's aridification on biogeographical and diversification patterns. Here, we use phylogenetic analyses to see whether this group of higher termites is monophyletic, which would indicate a single introduction event on the Australian continent. We also infer ancestral biomes to examine the impact of the expanding arid zone on species distributions and use diversification analyses to test whether there are changes in the rate of species accumulation coincident with periods of late Cenozoic climate change (e.g., during the "Hill Gap" and Plio-Pleistocene).

\section{Materials and Methods}

\section{Mitochondrial genome sequencing}

Sequences were obtained from a total of 87 AAG samples preserved in $70-100 \%$ ethanol or RNAlater, including samples from our own collections (sampled in 2016 and 2019) and the Australian National Insect Collection (ANIC). For collection details, see Supplemental Material, Tab. S1.

We used two different sequencing and assembly strategies: (1) long-range PCR followed by deep-amplicon sequencing and (2) ultra-low coverage (1X) whole-genome sequencing (WGS). For the first strategy, whole genomic DNA (gDNA) was extracted from soldier heads using the DNeasy Blood \& Tissue extraction kit (Qiagen, Hilden, Germany) following manufacturer's instructions. Long-range PCRs were performed with PrimeSTAR GXL DNA Polymerases (Takara Bio Europe). Initial sequences generated following Bourguignon et al. (2015) were used to develop more effective primers for this group using Primer3 (Untergasser et al., 2012) implemented in Geneious R10 ver.10.0.1 (Kearse et al., 2012). See Supplemental Material for primer sequences and PCR conditions. The resulting $\sim 8 \mathrm{~kb}$ and $\sim 10 \mathrm{~kb}$ fragments were mixed in equimolar concentrations and sequenced as 
paired-end 300 bp reads on an Illumina MiSeq at the Göttingen Genomics Laboratory (G2L, Germany). Amplicon sequencing reads were quality-trimmed using Trimmomatic (Bolger et al., 2014) and assembled with the SPAdes 3.13.0 (Nurk et al., 2013) plugin in Geneious Prime using default settings.

For the second strategy, gDNA was extracted from a pool of 4-6 individuals per colony (digestive tracts removed), using the Agencourt DNAdvance Magnetic Bead Kit (Beckman Coulter) or the MagAttract HMW DNA Kit (Qiagen). DNA quality was assessed visually using a 1\% agarose gel; quality and concentration were also checked with a Nanodrop 2000 Spectrophotometer (Thermo Fisher Scientific), and a Qubit 2.0 Fluorometer (Thermo Fisher Scientific). Whole genome sequencing (WGS) was performed on a MGISEQ-2000 (Beijing Genomics Institute, BGI, China) resulting in paired-end 150 bp reads. Reads were pre-trimmed by BGI using SOAPnuke1.5.5 (Chen et al., 2018).

To retrieve mitochondrial reads from WGS data, we filtered all reads against a customised database of termite whole mitochondrial genome sequences (mitogenomes, Tab. S1) using Kraken 2 (Wood et al., 2019). Filtered mitochondrial reads were assembled with MitoZ version 2.4 (Meng et al., 2019) using the 'all' module for paired-end data with default settings (read length: $150 \mathrm{bp}$; insert size: $300 \mathrm{bp}$ ). The resulting mitogenomes were visually checked in Geneious Prime 2020.2.3 (Kearse et al., 2012). Unresolved residues and gap characters were manually corrected and the MITOS web server was used for annotation (Bernt et al., 2013).

\section{Mitochondrial data set}

The final data set comprised 135 mitochondrial genomes (see Supplementary Material, Tab. S1): 87 Amitermes and Drepanotermes mitogenomes sequenced in this study and 48 sequences from $\mathrm{NCBI}$, including 15 Amitermes and Drepanotermes mitogenomes and 33 mitogenomes of outgroup taxa to root the phylogenetic inferences.

Control regions of mitogenomes were omitted, as they are generally poorly assembled with short reads due to their highly repetitive character. Each gene was aligned individually using the Muscle algorithm (Edgar, 2004) implemented in Geneious Prime with default settings. Protein-coding genes were aligned as codons. Although, there was no evidence for saturation at third codon positions of protein-coding genes (NumOTU $=32$, Iss $=0.265$, Iss.cAsym = 0.554) using Xia's method in DAMBE v.7.2.4 (Xia, 2018), a test for compositional homogeneity using p4 (Foster, 2004; 
https://github.com/pgfoster/p4-phylogenetics) detected heterogeneity among sequences at the third codon position (chi-square $=1332.07$; df $=372 ; \mathrm{p}<0.0001$ ). Therefore, we excluded those third codon positions from all further analyses resulting in a final concatenated sequence alignment partitioned into four subsets: (a) first, and (b) second codon positions of protein-coding genes; (c) 12S and 16S rRNA genes; and (d) tRNA genes.

\section{Genetic distances and phylogenetic relationships}

Principal Coordinates Analysis (PCoA) was used to visualize genetic (dis)similarity among AAG sequences. Thus, we excluded non-Amitermes sequences and Amitermes sequences from outside Australia from the final concatenated sequence alignment. SNPs were called with the R package 'adegenet' ver. 2.1.1 (Jombart, 2008; Jombart \& Ahmed, 2011) using R version 3.6.3 (R Core Team, 2020). The PCoA was performed in R with vegan ver. 2.5-6 (Oksanen et al., 2019).

The final concatenated sequence alignment was analyzed in a maximum likelihood framework using IQ-TREE ver. 2.0.6 (Minh et al., 2020). We used the implemented algorithm of PartitionFinder (Lanfear et al., 2012) to search for the best-fitting partitioning scheme, which increases model fit by reducing overparameterization. The model selection procedure was immediately followed by tree reconstruction ('-MFP+MERGE' command). We performed 1000 replicates each for both ultrafast bootstraps (ufBS) ('-bb' command) and SH-aLRT tests ('-alrt' command). Nodes were classified as "robust", if recovered support values for SH-aLRT/ufBS were $\geq 75 \%$.

To date our phylogeny, we used four termite fossils as internal calibrations (see Tab. S2): (1) †Nanotermes isaacae, (2) †Reticulitermes antiquus, (3) †Microcerotermes insularis and (4) $\dagger$ Amitermes lucidus. †Nanotermes isaacae is the oldest known Termitidae fossil and at least 47.8 million years old (Engel et al., 2011); we used it to calibrate the Termitidae + sister group. †Reticulitermes antiquus is known from Baltic amber (Engel et al., 2007) (minimum age of 33.9 million years) and likely represents a stem group Reticulitermes according to Bucek et al. (2019), so we used it to calibrate Reticulitermes + sister group. (3) †Microcerotermes insularis and (4) †Amitermes lucidus are both known from Dominican amber (minimum age of 13.8 million years) and their generic assignment is clearly established (Krishna \& Grimaldi, 2009). The fossil calibrations were implemented as exponential priors using the aforementioned minimum fossil ages as reported on the Paleobiology Database (www.paleobiodb.org; accessed 30 July 2020) as minimum age constraints. Soft maximum bonds ( $97.5 \%$ probability) were deliberately chosen to be very 
old (Tab. S2), because the fossil record of termites is highly fragmentary, which can lead to underestimated node ages (Ho \& Philips, 2009).

For each partition of the final concatenated sequence alignment, we used the bModelTest package (Bouckaert \& Drummond, 2017) to average over all transition/transversion split models (31 different models in total; see Bouckaert \& Drummond, 2017) implemented in BEAST 2.6.1 (Bouckaert et al., 2019) using reversible jump Markov Chain Monte Carlo (rjMCMC). This approach takes into account uncertainty in the model selection process and subsequent bias in estimates based on single models (Bouckaert et al., 2017). In all analyses, we used an uncorrelated lognormal relaxed clock model of rate variation across branches (Drummond et al., 2006) and a birth-death speciation process as tree prior.

We performed three independent MCMC runs, sampling tree and parameter values every 25,000 steps over a total of 500 million generations. Convergence and effective sample sizes were checked with Tracer v1.7.1. (Rambaut et al., 2018), with a quarter of samples removed as burn-in. MCMC runs were combined with LogCombiner v2.6.2 (Drummond \& Rambaut, 2007) and a maximum-clade-credibility tree was obtained using TreeAnnotator v2.6.0.

\section{Biogeographic history}

We used our time-calibrated tree to compare biogeographic models and estimate ancestral ranges using the maximum-likelihood approach implemented in the $R$ package BioGeoBEARS v.1.1.2 (Matzke, 2013). We compared three different biogeographic models implemented in BioGeoBEARS: DEC, DIVALIKE, and BAYAREALIKE. These biogeographic models include different cladogenetic processes: (1) DEC (Dispersal-Extinction-Cladogenesis) includes subset sympatry; (2) DIVALIKE (likelihood interpretation of DIVA) includes widespread vicariance; and (3) BAYAREALIKE (likelihood interpretation of BayArea) includes widespread sympatry. The best-fitting model was assessed with the Akaike Information Criterion (AIC; Akaike, 1974).

Prior to analysis, we excluded all outgroup taxa and non-Australian Amitermes. Additionally, we pruned the tree of splits younger than 1.5 million years, retaining only a single representative of each species/independent evolutionary unit to avoid spurious "speciation" events as recommended on the BioGeoBEARS website (http://phylo.wikidot.com/biogeobears-mistakes-to-avoid\#toc6). This resulted in a tree with 72 terminal tips, which were assigned to the four major biomes in Australia (modified from 
Fujita et al., 2010; abbreviated as follows: S, mesic south-western zone; A, arid zone; M, monsoonal tropics; and E, mesic eastern zone) depending on the collection site (Fig. 1c and Tab. S3). Where tips could be unambiguously attributed to a described species, occurrence records from the Atlas of Living Australia (http://www.ala.org.au. Accessed 10 July 2020) were used to assist biome assignment. We allowed a maximum of two biomes to form a species range, while excluding all combinations of non-adjacent biomes (i.e., "S+M" and "S+E"), which resulted in 9 possible ranges in total.

We used 100 Biogeographical Stochastic Mappings (BSMs) to obtain the overall probabilities of the anagenetic and cladogenetic events (Matzke, 2016; Dupin et al., 2017), which depend on the geographic distributions, the time-calibrated phylogeny, and the best-fitting model. This allowed us to quantify the relative role of dispersal and vicariance at cladogenesis in the diversification of the AAG.

\section{Model and rates of diversification}

The temporal pattern of lineage diversification was visually assessed with a semi log-scaled Lineage-through-time (LTT) plot in the R package phytools (Revell, 2012) using the pruned time-calibrated tree (see above), as well as 500 simulated LTTs assuming a pure-birth process of the same duration and resulting in the same total number of species. The $Y$ statistic (Pybus \& Harvey, 2000) was simultaneously calculated, which can detect whether the net diversification rate deviated over time from a pure birth model (standard normal distribution with a mean of 0 ). We conducted a Monte Carlo constant rates test (MCCR test; Pybus \& Harvey, 2000) implemented in the R package LASER (Rabosky, 2006), to account for incomplete sampling (Fordyce, 2010). The test mimicked incomplete sampling by randomly pruning taxa from phylogenies, which were simulated to the full size of the group (i.e., about 100 described species according to Krishna et al. (2013)). We used 10,000 replicates under the null hypothesis of a constant rate pure-birth diversification process.

In addition to the MCCR test, we compared the fitting of alternative evolutionary models in respect to our LTT plot using the run_diversification_analyses.R script (Condamine et al., 2018). This analytical pipeline includes the R packages RPANDA (Morlon et al., 2016) and DDD (Etienne et al., 2012). Both approaches take into account the absence of species (both extinct and missing from the phylogeny) and how this is likely to affect historical diversification rates. We used four different models, of which two assume constant diversification rates including the pure-Birth (or Yule) model assuming no extinction, and the constant rate birth-death model (CR) with extinction but constant rates of speciation and 
extinction over time and among lineages. The other two models assume diversity-dependence, namely the density-dependent linear (DDL+E) and the density-dependent exponential $(\mathrm{DDX}+\mathrm{E})$ models. Both models quantify diversification rates as functions of changes in species accumulation over time. The DDL+E model assumes a linear dependence of speciation rate with extinction $(E)$, while the $D D X+E$ model assumes an exponential dependence of speciation rate with extinction.

We fitted all models under three alternative scenarios to account for different proportions of missing species in our phylogeny. Although the number of species currently reported for the AAG is comparatively high, the 'true' diversity is likely much higher. Hence, we assumed that the group (a) consists of the currently reported number of species (100), (b) includes more species (150) than known today, and (c) is actually much larger than currently described (250). In other words, we assumed that the sampling fractions in our phylogeny were $72 \%$, $48 \%$, and $29 \%$, respectively. The AIC approach was used to evaluate the best-fitting model, reported as the bias-corrected AIC version (AICC; Burnham \& Anderson, 2002; Posada \& Buckley, 2004). To determine the goodness of fit of candidate evolutionary models, we used the lowest AICc score and $\triangle \mathrm{AICc}$ scores, where the differences between the lowest (or best) $\mathrm{AICC}$ and the AICc of each alternative model are calculated, and thus, the best model has $\triangle \mathrm{AICc}=0$.

To complement the model-fitting approach, we employed BAMM 2.5.0 (Bayesian Analysis of Macroevolutionary Mixtures; Rabosky et al., 2013; Rabosky, 2014; Rabosky et al., 2014; bamm-project.org), which can automatically detect diversity-dependence on phylogenetic trees, shifts in diversification rate through time, and key innovations. We ran BAMM for 100 million generations with default parameters and a burn-in of $25 \%$ using the same pruned time-calibrated tree as above. To account for incomplete taxon sampling, we implemented 0.72 as sampling fraction. Since prior settings can have a substantial impact on BAMM analyses (Moore et al., 2016), we used a gradient of values for the prior on the number of shifts in diversification (compound Poisson process), ranging from the default value of 1.0 (higher probability of no rate shift) to 0.1 (higher probability of multiple rate shifts), with a step of 0.1 . The best-fitting run (i.e., highest posterior probability for the number of shifts) was selected for downstream analyses. The R-package BAMMtools 2.1 (Rabosky et al., 2014) was used to check for convergence (ESS > 200) and mixing of the MCMC chain in each analysis. 


\section{Results}

\section{Genetic distances and phylogenetic relationships}

Phylogenetic reconstructions based on Bayesian and ML inferences consistently recovered a monophyletic AAG (> $85 \% \mathrm{SH}$-aLRT/ufBS values and posterior probabilities), which is sister to A. dentatus from Southeast Asia (Fig. 1). The PCoA indicated three major groups within the AAG (Fig. 1): Amitermes group 1 (AG1), Amitermes group 2 (AG2), and Drepanotermes (DRE). The latter two formed independent monophyletic crown groups nested within the paraphyletic group AG1, which were well-supported in all phylogenetic analyses (> $95 \%$ SH-aLRT/ufBS values and posterior probabilities; Figs. 1 and S1 \& 2).

Divergence estimates, based on the model-averaging approach (bmodeltest) without third codon positions, dated the split between the AAG and the Southeast Asian species at 10.99 Mya (95\% HDP: 9.52-12.81 Mya) (Fig. S2). Two major divergence events, Drepanotermes at 6.5 Mya (95\% HDP: 5.6-7.67 Mya) and AG2 at 5.55 Mya (95\% HDP: 4.77-6.45 Mya), correspond roughly to the end of the paleoclimatic 'Hill Gap' (10-6 Mya) in the late Miocene (Fig. S2). An estimated $12 \%$ of DRE and $53 \%$ of AG2 lineages diverged during the Pliocene ( 5.3-2.6 Mya) compared to $33 \%$ of AG1 lineages, while recovered divergence time for 35 out of 95 lineages within the AAG were $<1.5$ Mya (Fig. S2).

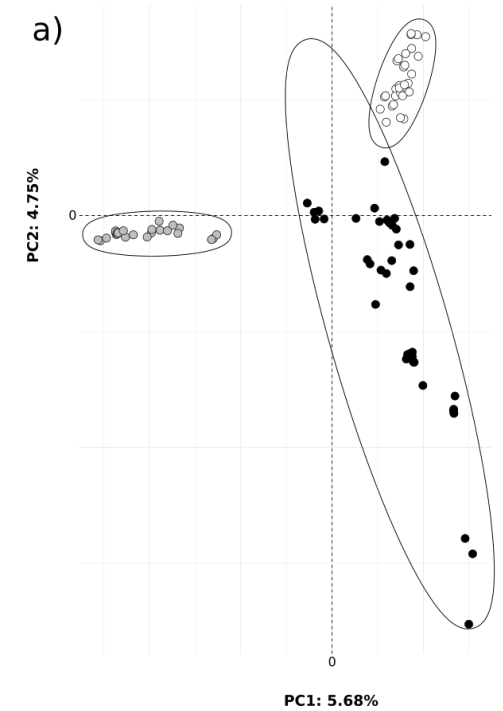

b)

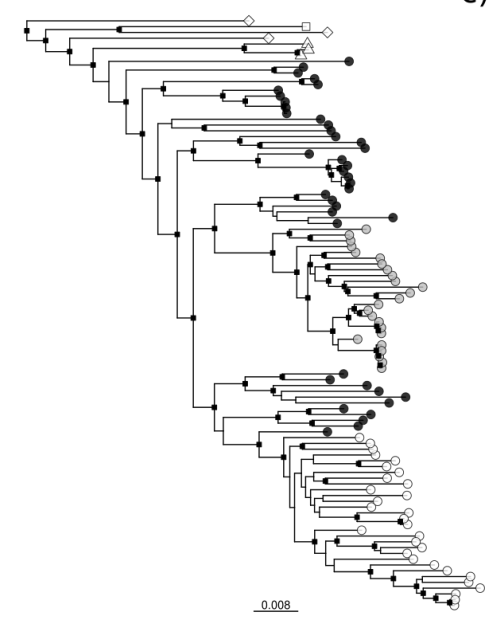

c)

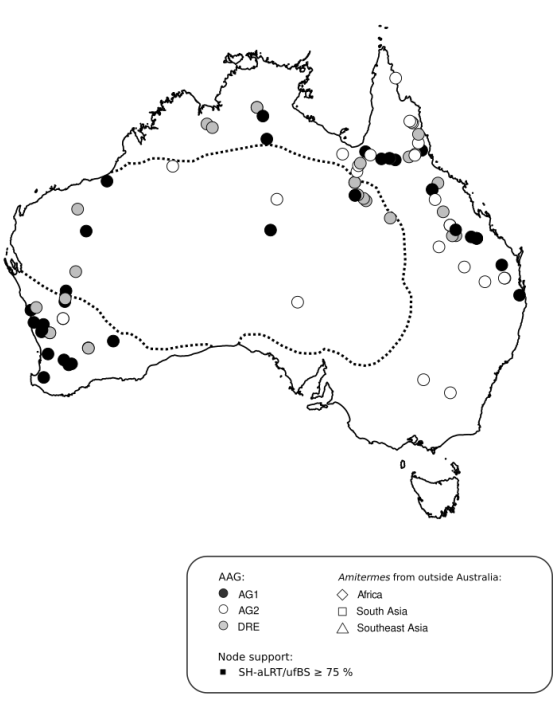

Figure 1: a) The PCoA showed three distinct genetic clusters within the AAG, b) two of which (DRE and AG2) are recovered as monophyletic by the maximum likelihood analysis. c) Map shows sampling locations of AAG taxa included in this study in relation to the arid zone (dashed line; modified from Fujita et al., 2010). 


\section{Biogeographic history}

The AIC model selection favored the DIVALIKE model, which was 1.8 AIC units lower than DEC and 29.1 AIC units lower than BAYAREALIKE (Tab. 1). The models that included vicariant processes (DEC and DIVALIKE) gave very similar histories compared to the BAYAREALIKE model (results under DEC and BAYAREALIKE are available in Fig. S3). We expected that vicariant speciation played a substantive role in the evolution of the AAG, because it has shaped the evolutionary trajectory of many arid zone taxa (Cracraft, 1982; Crisp \& Cook, 2007; Rabosky et al., 2007).

Table 1: Summary statistics of three biogeographic models estimated using BioGeoBEARS. The DIVALIKE model (in bold) was selected for downstream analyses based on $\triangle \mathrm{AIC}$ scores.

\begin{tabular}{l|cccccc} 
Model & LnL & $\begin{array}{c}\text { Number of } \\
\text { parameters }\end{array}$ & $\boldsymbol{d}$ & $\mathbf{e}$ & AIC & $\boldsymbol{\Delta}$ AIC \\
\hline DEC & -143.8 & 2 & 0.06 & 0.04 & 291.8 & 1.8 \\
DIVALIKE & -142.9 & 2 & 0.07 & 0.03 & 290 & 0 \\
BAYAREALIKE & -157.4 & 2 & 0.07 & 0.13 & 319.1 & 29.1
\end{tabular}

Ancestral range reconstruction based on the DIVALIKE model estimated that the most probable ancestral range for the AAG is a combination of the monsoonal tropics + arid zone $(P=0.49)$ followed by the monsoonal tropics $(0.29)$, and other state combinations $(0.32)$ (Fig. ). The two monophyletic crown groups AG2 and DRE were inferred to have different ancestral ranges: the latter most likely originated in the mesic south-western zone + arid zone (0.46) followed by the arid zone (0.39); while the former probably in north-northeastern Australia (monsoonal tropics + arid zone; 0.61) (Fig. 2). 


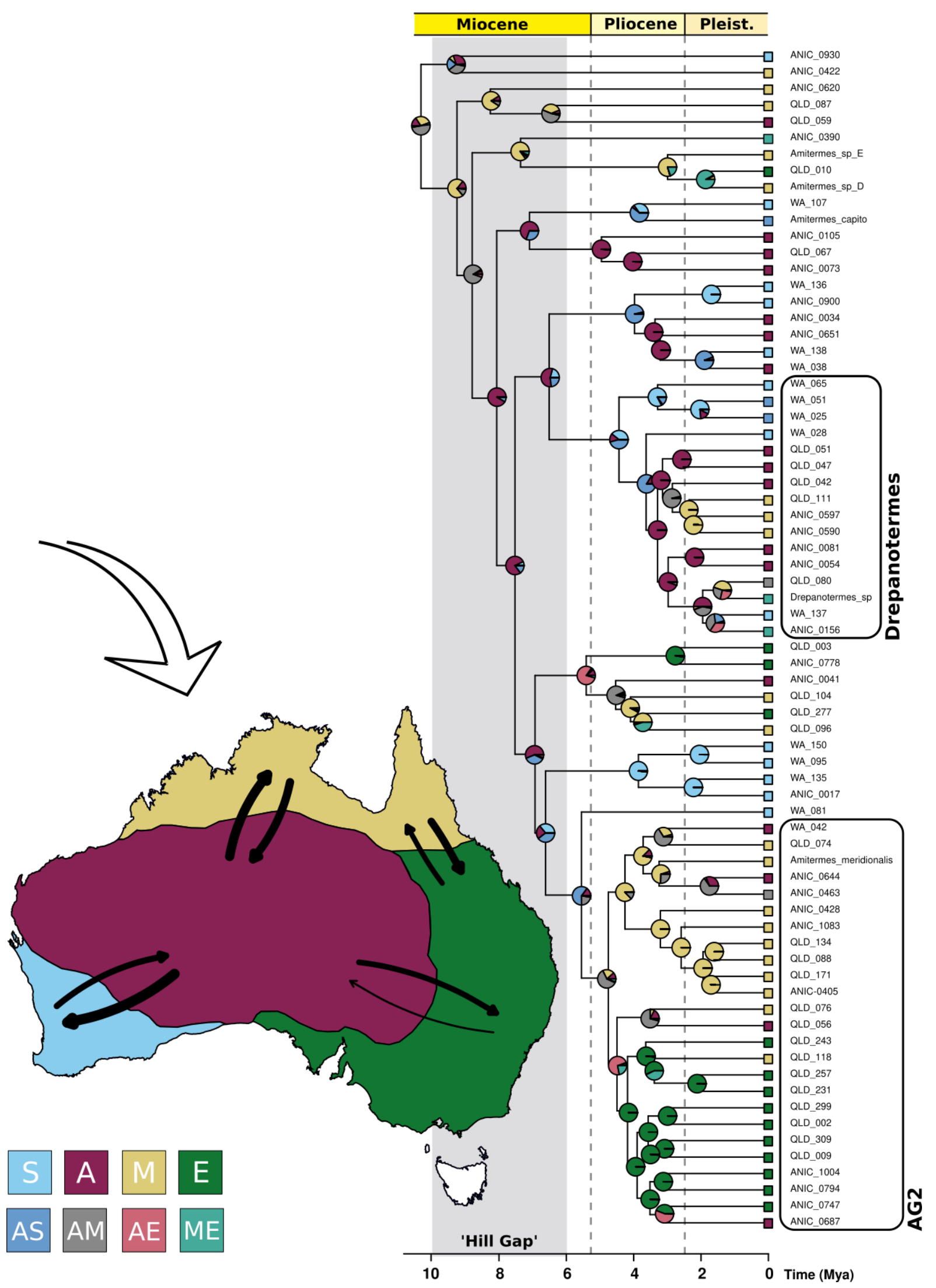

Figure 2: Ancestral range reconstruction of the AAG based on the DIVALIKE model. Relative probabilities of ancestral areas are shown in pie charts at nodes. Colored squares identify biomes: $\mathrm{S}$, mesic south-western zone; $\mathrm{A}$, arid zone; $\mathrm{M}$, monsoonal tropics; $\mathrm{E}$, mesic eastern zone. Combinations of biomes (e.g. AS, arid zone + mesic south-western zone) are also indicated in colored squares, but not shown on the map. The "Hill Gap" is shaded in 
grey. Black arrows indicate direction and frequency of dispersal events between biomes and line thickness indicates the number of event counts summarized with biogeographical stochastic mapping (BSM) (see Tab. S4). The white arrow indicates the putative arrival direction of the ancestor of the AAG (see Discussion). AAG taxa collected in this study are given with sample ID (see Tab. S1).

The BSM results indicate a complex biogeographical history, driven largely by within-area speciation and dispersal events $(46.2 \%$ and $34.6 \%$ of the total number of events) rather than vicariance events (19.2\%; Tab. 2). The highest number of dispersals occurred from the arid zone to the mesic south-western zone ( $\sim 9$ of 38 total estimated events), next highest was movements from the arid zone to the monsoonal tropics ( 7 of 38 ) and from the monsoonal tropics to the arid zone ( $\sim 6$ of 38) (Tab. S4). More than half of all estimated dispersal events $(52.1 \%)$ started in the arid zone, with the next common source being the monsoonal tropics (28.5\%) (Tab. S4 and Fig. 2). Most of these movements were directed towards the arid zone $(28.1 \%)$, followed closely by the monsoonal tropics and the mesic south-western zone (26.6\% and $24.6 \%$, respectively) (Tab. S4 and Fig. 2).

Table 2: Summary counts of 100 BSMs based on the DIVALIKE model using BioGeoBEARS. The estimated number of events for the different types are given in mean numbers with standard deviations (SD) and percentages.

\begin{tabular}{l|cccc} 
& Range expansion & Within-area speciation & Vicariance & $\begin{array}{c}\text { Total number of } \\
\text { events }\end{array}$ \\
\hline mean & 37.51 & 50.15 & 20.85 & 108.5 \\
SD & \pm 1.7 & \pm 1.91 & \pm 1.91 & \pm 1.7 \\
$\% \quad$ of $\quad$ total & & & & \\
events & 34.6 & 46.2 & 19.2 & 100
\end{tabular}

\section{Model and rates of diversification}

The LTT plot suggests two pulses of increased diversification followed by declines: (1) a first slight increase occurring 9-6.5 Mya with a decline 6.5-5.5 Mya; and (2) a subsequent abrupt, steep incline ( 4.5-3 Mya) that exceeds the $95 \%$ confidence interval followed by a slowdown to the present day. The MCCR test showed a significantly negative $\mathrm{y}$ statistic $(-2.36, p=9.999 e-05)$ indicating non-constant species accumulation over time, as shown by the LTT plot (Fig. 3). 


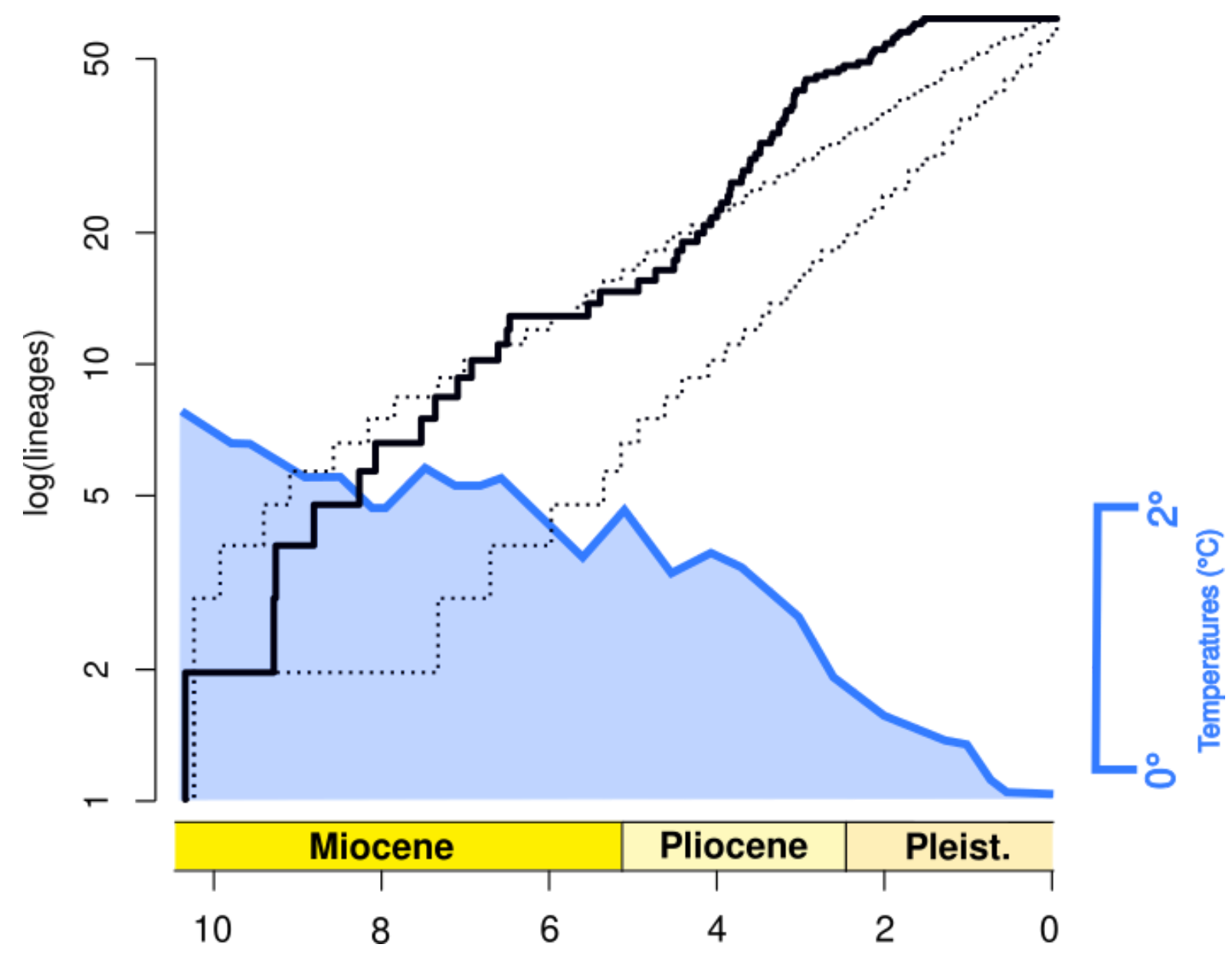

Figure 3: The LTT curve (black line), plotted against deep ocean temperatures (blue; modified from Zachos et al., 2001), shows two pulses of rapid diversification, which fall outside the $95 \%$ confidence interval generated by simulated LTTs (dashed lines).

The diversity-dependent linear model $(D D L+E)$ was the best-fitting estimate of evolutionary diversification within the AAG (Tab. 3), based on four candidate models used in the maximum-likelihood diversification analyses. This supports again that a non-constant mode of diversification has shaped the evolutionary trajectory of the AAG. The same holds true when we assumed that only $48 \%$ or $29 \%$ of the 'true' diversity of the group was sampled in the phylogeny (Tab. 3), indicating that the results are robust against potential missing species. 
Table 3: Alternative evolutionary models were fitted to the diversification history of the AAG. Included models are Yule (pure-birth model), CR (constant-rate birth death model), DDL+E (density-dependent linear diversification model), and DDX+E (density-dependent exponential diversification mode). The best-fit of models are based on $\triangle \mathrm{AICc}$ scores.

\begin{tabular}{|c|c|c|c|c|c|}
\hline Model & $\log L$ & $\lambda$ & $\boldsymbol{\mu}$ & AlCc & $\triangle \mathrm{AICc}$ \\
\hline \multicolumn{6}{|c|}{$72 / 100$} \\
\hline Yule & -167 & 0.29 & 0 & 336 & 27.7 \\
\hline CR & -167 & 0.29 & 0 & 338.1 & 29.8 \\
\hline DDL+E & -151 & 0.74 & $5.9 \mathrm{e}-05$ & 308.3 & 0 \\
\hline $\mathrm{DDX}+\mathrm{E}$ & -179.5 & 0.57 & 0.35 & 365.3 & 57 \\
\hline \multicolumn{6}{|c|}{$72 / 150$} \\
\hline Yule & -162.8 & 0.36 & 0 & 327.6 & 17.5 \\
\hline CR & -162.8 & 0.36 & 0 & 329.7 & 19.6 \\
\hline DDL+E & -151.9 & 0.74 & $3.8 \mathrm{e}-06$ & 310.1 & 0 \\
\hline $\mathrm{DDX}+\mathrm{E}$ & -161.9 & 1.52 & 0.12 & 330.1 & 20 \\
\hline \multicolumn{6}{|c|}{$72 / 250$} \\
\hline Yule & -158.4 & 0.45 & 0 & 318.78 & 0.98 \\
\hline CR & -158.4 & 0.45 & 0 & 320.9 & 3.1 \\
\hline DDL+E & -155.7 & 1.01 & 0.16 & 317.8 & 0 \\
\hline $\mathrm{DDX}+\mathrm{E}$ & -158.6 & 1.15 & 0.04 & 323.52 & 5.72 \\
\hline
\end{tabular}

BAMM analyses showed no major shifts in the rate of diversification within the AAG (Tab. S5 and Fig. S4), irrespective of the prior value that governs the number of rate shifts. The best-fitting run with the highest probability was fixed at 0.1 (Tab. S5). Consistent with a pattern of rapid diversification, the rate of diversification decreased markedly over time (Fig. S4), while the extinction rate remained near zero (mean extinction rate of $\sim 0.05$; Fig. S4)

\section{Discussion}

The AAG is monophyletic and sister to $A$. dentatus from Southeast Asia. This indicates a single arrival event on the Australian continent through the Southeast Asian Archipelago about 11-10 Mya. This northern route is thought to have facilitated the dispersal of many insect species (Condamine et al., 2013, Matos-Maraví et al., 2018), after the Southeast Asian and Australian Plates collided 25-20 Mya (Hall, 2002). Our findings are in agreement with earlier results (Bourguignon et al., 2017); the missing lineages Ahamitermes, 
Incolitermes, and Invasitermes, are endemic inquilines in the nests of other termites (six species in total; Gay, 1955; Calaby, 1956; Abensperg-Traun \& Perry, 1998) and share derived traits such as the near or complete loss of soldiers (Gay, 1968) and highly specialised mandibles (Miller, 1984). This suggests that they diversified in situ on the continent, similar to AG2 and Drepanotermes. In our PCoA, AG2 and Drepanotermes were clearly separated from $A G 1$ and recovered in all phylogenetic analyses with high nodal support. They are nested among lineages of AG1, rendering Amitermes, as currently described, paraphyletic, which confirms the long-standing notion that these genera are derived from Amitermes (Hill, 1942; Watson, 1982; Miller, 1984).

Our reconstruction of the biogeographical history indicates that the ancestral range of the AAG is a combination of the monsoonal tropics + arid zone. This does not necessarily conflict with our phylogenetic reconstructions, but simply reflects the likely geographic distribution of the most recent common ancestor of extant AAG species. Irrespective of where the group originated, the available evidence (including deep nodes in our phylogeny) indicates that Australia's monsoon region was the starting point for the radiation of the AAG across the continent. Accordingly, early lineages that speciated in situ may have been preadapted to seasonal climates, as their Southeast Asian ancestor evolved under similar climatic conditions (Bowman et al., 2010), allowing them to quickly expand their distributions in the monsoonal tropics.

Our estimate of ancestral ranges using the best-fitting model DIVALIKE suggests around 37 dispersal events during the radiation of the AAG, with 31 events occurring from or to the arid zone. While this may seem to be a very high number considering termites' generally poor dispersal ability (Eggleton, 2000), our reconstructions of ancestral ranges and inference of biological processes (i.e., within-area speciation, range expansion, and vicariance) need to be considered in the context of gradual biome turnover during the last 15 million years in Australia. Early in the AAG radiation, environmental and climatic conditions were much different than today. For example, the arid zone as we know it, with iconic sand desert landscapes, is no older than one million years (Fujioka \& Chappell, 2010) and formed in response to increasing aridification in the Miocene and Pleistocene (Byrne et al., 2008; 2018). Even today's stony deserts did not develop until the end of the Pliocene ( 3-2 Mya; Fujioka et al., 2005), while central Australia seems to have been covered by open woodlands and gallery forests at least since the late Miocene (Mao \& Retallack, 2019; but see also Travouillon et al., 2009). This means the initial radiation of the AAG during the late Miocene occurred before major biogeographical barriers, e.g. the Great Sandy Desert in Western Australia, developed. Such a relatively benign habitat likely fostered successful 
expansion into or through the evolving arid zone and frequent dispersal into other biomes. Open sclerophyllous forests, including Acacia and Eucalyptus, have been widespread since the Paleogene (summarized in Crisp \& Cook, 2013); these plants are primary food sources of AAG taxa in semi-arid and arid regions of Australia (Andersen \& Jacklyn, 1993; Abensperg-Traun et al., 1995) and their widespread distribution certainly also contributed to successful range expansion of these termites.

As expected, within-area speciation is the most frequent type of event recovered in the BSM analysis. This reflects the large size of the regions and the associated predominance of lineages endemic to individual biomes. Such geographic restriction is in contrast to species occurrence records for some AAG taxa in our study, however high inter- and intraspecific variability made taxonomic reconciliation with historical morphology-based records impracticable. Nonetheless, shallow Plio-Pleistocene divergences in our phylogeny, particularly seen in $A G 2$, tend to occur in close geographic proximity, likely reflecting phylogeographic structuring of species in response to habitat heterogeneity caused by intensifying aridification (Fujioka \& Chappell, 2010).

The lowest number of events was inferred for vicariance, occurring about half as often as dispersal events. Biogeographic barriers have played an important role in shaping the present-day distribution of the continent's plant and animal species (Crisp \& Cook, 2007; Owen et al., 2017; Harms et al., 2019). They are mainly attributed to increasing aridity over the last 20 million years, particularly in central Australia (Cracraft, 1982), and to dramatic sea level fluctuations during Pleistocene interglacial periods (Zachos et al., 2001). We observed a strong correspondence between the frequency of vicariance events in the Plio-Pleistocene and the diversification of arid lineages from mesic and tropical ancestors, suggesting that the formation of potential vicariance barriers resulted in repeated allopatric speciation (Cracraft, 1982). This is consistent with complex diversification dynamics shown in other organisms (summarized in Byrne et al., 2018). However, we also observed diversification in the opposite direction in which mesic and tropical species diverged from arid ancestors, for example in Drepanotermes. Such a pattern has been recently shown in spinifex grasses (Toon et al., 2015), commonly harvested by Drepanotermes spp., which might indicate that the latter co-diversified with the former.

The LTT plot suggests that two pulses of rapid diversification occurred during the evolution of the AAG, corresponding to the initial radiation of early lineages (belonging to AG1) and to the radiation of the two derived groups, AG2 and Drepanotermes. Several factors may have separately or jointly influenced the evolutionary trajectory of the AAG, including these two 
surges of diversification. We will consider four possible factors in detail: (1) extinction, (2) predation, (3) key innovations, and (4) availability of niche space.

First, we consider it unlikely that an increase in extinction is responsible for the observed pattern, as the AAG diversified in the near absence of extinction. Legendre and Condamine (2018) showed that extinction rates are in general exceptionally low in termites compared to other dictyoptera, which is related to their eusocial lifestyle. Nonetheless, there are long naked branches in our phylogeny indicative of extinction events, and the current distribution of sister species in opposite corners of Australia suggests the occurrence of repeated range expansions and contractions coupled with extinction in the past. Yet there is no evidence that a mass extinction event took place that could have spurred rapid diversification (Losos, 2010). Instead, extinction seems to have been rare and sporadic within the AAG.

Second, although termites are consumed by many different animals including mammals, ants, and lizards (Holt, 1990; Abensperg-Traun \& De Boer, 1992; dos Reis et al., 2012), predator-prey interactions are poorly understood (Noirot \& Darlington, 2000). However, most termite-eating animals are found in the semi-arid and arid zones of Australia, and in those regions, termites make up the greatest proportions of their diets (Abensperg-Traun, 1994; Palmer, 2010). Termite-eating lizards, in particular, are abundant in the arid zone (Morton \& James 1988), and there seems to be a positive link between lizard and termite richness in central Australia (Pianka, 1981; Colli et al., 2007). While Amitermes soldiers have been described as generally "the embodiment of cowardice and uselessness" (Hill, 1922), Drepanotermes soldiers are moderately large, produce copious amounts of defensive secretions, and have long sickle-shaped mandibles. They are numerous and can be highly effective against predatory ants (e.g. Iridomyrmex: Greenslade, 1970; for discussion of temporary nest occupation see Holt, 1990) as well as other insects and spiders (Hill, 1922) and vertebrates (echidnas: Abensperg-Traun \& De Boer, 1992; lizards: Hill, 1922). This suggests a response to predation pressure during arid-zone evolution. Although it is very unlikely that predation alone can explain the macroevolutionary dynamics that shaped the diversification of the AAG, its impact should not be underestimated (see Nosil \& Crespi, 2006; Hautmann, 2020).

Third, key innovations have been frequently invoked to explain high levels of species diversity (Yoder et al., 2010), and in a broad sense, any trait that promotes increasing diversification can qualify (Rabosky, 2017). Strikingly, the majority of mound-building species either belong to AG2 (e.g. A. meriodionalis) or Drepanotermes (e.g. D. tamminensis), which diversified rapidly in the Plio-Pleistocene. This may indicate a causal link between the 
evolution of mound-building and the second diversification surge in the early Pliocene. However, BAMM inferences showed no rate shift(s) associated with the acquisition of this trait; indeed no rate shifts at all were detected by BAMM. Regardless of whether mound-building is a key innovation or a subsequent adaptive change, mound-building species have become ecologically dominant in mesic and tropical regions (Andersen \& Jacklyn, 1993; Abensperg-Traun \& Perry, 1998), indicating an important role in the rapid diversification of AG2 and Drepanotermes.

Fourth, the two bursts in diversification rate coincide with major environmental and climatic changes in the late Miocene and early Pliocene. The contraction of rainforests and expansion of sclerophyllous vegetation in the late Miocene and the brief return of warm and wet conditions in the early Pliocene, including the re-expansion of rainforests (Byrne et al., 2008), represent an unparalleled source of ecological opportunity. Such a scenario is known to trigger rapid diversification (Losos, 2010). It is mainly invoked in island systems where resources are abundant and interspecific competition low (Gillespie, 2016), as opposed to continents with complex and competitive habitats (Rabosky \& Lovette, 2008). However, Pincheira-Donoso et al. (2015) has shown that dramatic environmental changes, brought about by the Andean uplift $\sim 25$ Mya, facilitated the rapid continental radiation of Liolaemus lizards. The intensifying aridification that caused gradual biome turnover on the Australian continent in the last 20 million years may have created similar ecological "windows of opportunity" that closed as niches filled. This is supported by recovering the DDL+E model as the best-fitting estimate of evolutionary diversification within the AAG, implying a declining rate of diversification due to species accumulation and niche saturation over time.

Of course, incomplete taxon sampling can also contribute to patterns of decreasing diversification (Cusimano \& Renner, 2010), such as the Pleistocene plateau in the LTT plot. We would expect this apparent rate change to be less abrupt with greater representation from the central deserts and NW Western Australia. In addition, Amitermes includes many soil-dwelling (and possibly soil-feeding) species, which are more often under-sampled in phylogenetic studies (Chouvenc et al., 2021). Despite these limitations, the large number of recent (< 2 Mya) splits reflect ongoing diversification. This can also be observed in the closely related species and species complexes of the AAG (e.g. Drepanotermes perniger, Watson \& Perry, 1981), often in sympatric associations, and the high degree of endemism (Gay, 1968; Watson \& Gay, 1991; Watson \& Perry, 1981; Abensperg-Traun \& Perry, 1998).

Our results indicate that the AAG has an immense potential to adapt to changing climatic conditions. Because the activity of termites is thought to increase the resistance of semi-/arid 
environments under the prospect of future climate change (Bonachela et al., 2015), the AAG could play an important role in maintaining Australia's ecosystems in the face of human-mediated climate change. Current climate models predict a change over the next 50 years in Australia nearly as great as that of the last 10 million years with mean annual temperature increases of $1-6^{\circ} \mathrm{C}$ (Hughes, 2003). Future studies will show whether the AAG can adapt as quickly as it has in the past to keep up with the current pace of global climate change.

\section{Conclusion}

This study illuminates the evolutionary history of the most speciose termite group in Australia and is one of the few biogeographical studies with a continent-wide focus. Consistent with dispersal patterns in other insects (Yeates \& Cassis, 2017), the group's ancestor arrived in Australia via a northern route from Southeast Asia. Despite being poor dispersers, early lineages were apparently able to expand their range quickly under favorable conditions in the late Miocene. The progressive aridification of the Australian continent and expansion of the arid zone, especially in the last 4 million years, has shaped the evolutionary trajectory of many, if not all, of the AAG lineages and continues to shape them. Multiple lines of evidence suggest that two pulses of rapid diversification occurred during the evolution of the AAG coincident with past global climate change. There are many studies showing that the intensifying aridification of the Australian continent triggered rapid diversification (summarized in Byrne et al., 2018), and this is the first study to do so for Australian termites. Congruent with diversity-dependent patterns, species accumulation declined likely due to progressive niche saturation. However, other factors such as key innovations or predation certainly play(ed) an important role in the rapid diversification of the AAG, however it remains to be seen to what extent.

Additional taxon sampling in underrepresented semi-/arid regions is necessary to answer open questions related to migration patterns during initial expansion across Australia and later diversification within the arid zone. This and other studies of the Australian fauna demonstrate the resilience of termites against naturally occurring environmental change. In this case, the aridification of the Australian continent was not an evolutionary dead end for the AAG but rather the impetus for adaptation and diversification. 


\section{Author contributions}

B.H. and T.R.H. designed research; B.H. and T.R.H. collected samples and determined species. B.H. and L.S. performed wet lab work. B.H. and A.B. analyzed data with input from T.R.H. B.H., A.B., S.S., and T.R.H. contributed to data interpretation and analyses. B.H. and T.R.H. wrote the paper with input from all authors.

\section{Acknowledgements}

We like to thank Stephen Cameron for providing termite samples and we are grateful to Fabien Condamine for helpful insights into diversification analysis.

\section{Data availability}

Mitochondrial genome sequences collected in this study will be deposited in GenBank.

\section{References}

Abensperg-Traun, M., De Boer, E. S. (1992). The foraging ecology of a termite-and ant-eating specialist, the echidnaTachyglossus aculeatus(Monotremata: Tachyglossidae). Journal of Zoology, 226(2), 243-257.

Abensperg-Traun, M. (1994). The influence of climate on patterns of termite eating in Australian mammals and lizards. Australian Journal of Ecology, 19(1), 65-71.

Abensperg-Traun, M., Steven, D. (1997). Latitudinal gradients in the species richness of Australian termites (Isoptera). Australian Journal of Ecology, 22(4), 471-476.

Abensperg-Traun, M., Perry, D.H. (1998). Distribution and characteristics of mound-building termites (Isoptera) in Western Australia. Journal of the Royal Society of Western Australia, $81,191-200$.

Akaike, H. (1974). A new look at the statistical model identification. IEEE Transactions on Automatic Control, 19(6), 716-723.

Andersen, A. N. (2016). Ant megadiversity and its origins in arid Australia. Austral Entomology, 55, $132-137$. 
Andersen, A. N., Jacklyn, P. (1993). Termites of the top end. Australia: CSIRO Publishing.

Arab, D. A., Namyatova, A., Evans, T. A., Cameron, S. L., Yeates, D. K., Ho, S. Y. W., \& Lo, N. (2017). Parallel evolution of mound-building and grass-feeding in Australian nasute termites. Biology Letters, 13(2), 20160665.

Barden, P., Ware, J. L. (2017). Relevant Relicts: The Impact of Fossil Distributions on Biogeographic Reconstruction. Insect Systematics and Diversity, 1(1), 73-80.

Barrett, Michelle Dianne; Williams, Matthew Russell. Distribution of the Western Petalura dragonfly Petalura hesperia Watson in Western Australia. Pacific Conservation Biology; Clayton, 4(2), 149-154.

Bernt, M., Donath, A., Jühling, F., Externbrink, F., Florentz, C., Fritzsch, G., ... Stadler, P. F. (2013). MITOS: Improved de novo metazoan mitochondrial genome annotation. Molecular Phylogenetics and Evolution, 69(2), 313-319.

Bonachela, J. A., Pringle, R. M., Sheffer, E., Coverdale, T. C., Guyton, J. A., Caylor, K. K., ... Tarnita, C. E. (2015). Termite mounds can increase the robustness of dryland ecosystems to climatic change. Science, 347(6222), 651-655.

Bouckaert, R. R., Drummond, A. J. (2017). bModelTest: Bayesian phylogenetic site model averaging and model comparison. BMC Evolutionary Biology, 17(1), 42.

Bouckaert, R., Vaughan, T. G., Barido-Sottani, J., Duchêne, S., Fourment, M., Gavryushkina, A., ... Drummond, A. J. (2019). BEAST 2.5: An advanced software platform for Bayesian evolutionary analysis. PLOS Computational Biology, 15(4), e1006650.

Bourguignon, T., Lo, N., Cameron, S. L., Šobotník, J., Hayashi, Y., Shigenobu, S., ... Evans, T. A. (2015). The Evolutionary History of Termites as Inferred from 66 Mitochondrial Genomes. Molecular Biology and Evolution, 32(2), 406-421.

Bourguignon, T., Lo, N., Šobotník, J., Ho, S. Y. W., Iqbal, N., Coissac, E., ... Evans, T. A. (2017). Mitochondrial Phylogenomics Resolves the Global Spread of Higher Termites, Ecosystem Engineers of the Tropics. Molecular Biology and Evolution, 34(3), 589-597.

Bowman, D. M. J. S., Brown, G. K., Braby, M. F., Brown, J. R., Cook, L. G., Crisp, M. D., .. Ladiges, P. Y. (2010). Biogeography of the Australian monsoon tropics. Journal of Biogeography, 37(2), 
201-216.

Bucek, A., Šobotník, J., He, S., Shi, M., McMahon, D. P., Holmes, E. C., .. Bourguignon, T. (2019). Evolution of Termite Symbiosis Informed by Transcriptome-Based Phylogenies. Current Biology, 29(21), 3728-3734.

Burnham, K. B., Anderson, D. (2002) Model selection and multi-model inference: a practical information-theoretic approach. New York, Springer Publishing.

Byrne, M., Yeates, D. K., Joseph, L., Kearney, M., Bowler, J., Williams, M. A. J., ... Wyrwoll, K.-H. (2008). Birth of a biome: Insights into the assembly and maintenance of the Australian arid zone biota. Molecular Ecology, 17(20), 4398-4417.

Byrne, Margaret, Steane, D. A., Joseph, L., Yeates, D. K., Jordan, G. J., Crayn, D., .. Weston, P. H. (2011). Decline of a biome: Evolution, contraction, fragmentation, extinction and invasion of the Australian mesic zone biota: Evolution of the Australian mesic zone biota. Journal of Biogeography, 38(9), 1635-1656.

Byrne M., Joseph L., Yeates D.K., Roberts J.D., Edwards D. (2018) Evolutionary History. In: Lambers H. (eds) On the Ecology of Australia's Arid Zone. Springer, Cham.

Calaby, J. H. (1956). The distribution and biology of the genus Ahamitermes (Isoptera). Australian Journal of Zoology, 4(2), 111-124.

Calaby J.H., Gay F.J. (1959) Aspects of the Distribution and Ecology of Australian Termites. In: Keast A., Crocker R.L., Christian C.S. (eds) Biogeography and Ecology in Australia. Monographiae Biologicae. Springer, Dordrecht.

Cardillo, M., Weston, P. H., Reynolds, Z. K. M., Olde, P. M., Mast, A. R., Lemmon, E. M., .. Bromham, L. (2017). The phylogeny and biogeography of Hakea (Proteaceae) reveals the role of biome shifts in a continental plant radiation. Evolution, 71(8), 1928-1943.

Cassis, G., Laffan, S. W., Ebach, M. C. (2017). Biodiversity and Bioregionalisation Perspectives on the Historical Biogeography of Australia. In Ebach, M. (Ed.). Handbook of Australasian Biogeography. Boca Raton: CRC Press.

Chen, Y., Chen, Y., Shi, C., Huang, Z., Zhang, Y., Li, S., .. Chen, Q. (2018). SOAPnuke: A MapReduce acceleration-supported software for integrated quality control and preprocessing of high-throughput sequencing data. GigaScience, 7(1). 
Chouvenc, T., Šobotník, J., Engel, M. S., Bourguignon, T. (2021). Termite evolution: Mutualistic associations, key innovations, and the rise of Termitidae. Cellular and Molecular Life Sciences.

Condamine, F. L., Toussaint, E. F. A., Cotton, A. M., Genson, G. S., Sperling, F. A. H., Kergoat, G. J. (2013). Fine-scale biogeographical and temporal diversification processes of peacock swallowtails (Papilio subgenus Achillides) in the Indo-Australian Archipelago. Cladistics, 29(1), 88-111.

Condamine, F. L., Antonelli, A., Lagomarsino, L. P., Hoorn, C., Liow, L. H. (2018). Teasing apart mountain uplift, climate change and biotic drivers of species diversification. In C. Hoorn, A. Perrigo, A. Antonelli (Eds.), Mountains, Climate and Biodiversity. Hoboken, NJ: John Wiley Sons.

Coventry, R., Holt, J., Sinclair, D. (1988). Nutrient cycling by mound building termites in low fertility soils of semi-arid tropical Australia. Soil Research, 26(2), 375.

Cracraft, J. (1982). Geographic Differentiation, Cladistics, and Vicariance Biogeography: Reconstructing the Tempo and Mode of Evolution. Integrative and Comparative Biology, 22(2), 411-424.

Crisp, M., Cook, L., Dorothy, S. (2004). Radiation of the Australian flora: what can comparisons of molecular phylogenies across multiple taxa tell us about the evolution of diversity in present-day communities? Philosophical Transactions of the Royal Society B: Biological Sciences, 359, 1551-1571.

Crisp, M. D., Cook, L. G. (2007). A congruent molecular signature of vicariance across multiple plant lineages. Molecular Phylogenetics and Evolution, 43(3), 1106-1117.

Cusimano, N., Renner, S. S. (2010). Slowdowns in Diversification Rates from Real Phylogenies May Not be Real. Systematic Biology, 59(4), 458-464.

dos Reis, M., Inoue, J., Hasegawa, M., Asher, R. J., Donoghue, P. C. J., Yang, Z. (2012). Phylogenomic datasets provide both precision and accuracy in estimating the timescale of placental mammal phylogeny. Proceedings of the Royal Society B: Biological Sciences, 279(1742), 3491-3500.

Drummond, A. J., Ho, S. Y. W., Phillips, M. J., Rambaut, A. (2006). Relaxed Phylogenetics and Dating with Confidence. PLOS Biology, 4(5), e88. 
Drummond, A. J., Rambaut, A. (2007). BEAST: Bayesian evolutionary analysis by sampling trees. BMC Evolutionary Biology, 7(1), 214.

Dupin, J., Matzke, N. J., Särkinen, T., Knapp, S., Olmstead, R. G., Bohs, L., Smith, S. D. (2017). Bayesian estimation of the global biogeographical history of the Solanaceae. Journal of Biogeography, 44(4), 887-899.

Edgar, R. C. (2004). MUSCLE: Multiple sequence alignment with high accuracy and high throughput. Nucleic Acids Research, 32(5), 1792-1797.

Eggleton P. (2000) Global Patterns of Termite Diversity. In: Abe T., Bignell D.E., Higashi M. (eds) Termites: Evolution, Sociality, Symbioses, Ecology. Springer, Dordrecht.

Engel, M. S., Grimaldi, D. A., Nascimbene, P. C., Singh, H. (2011). The termites of Early Eocene Cambay amber, with the earliest record of the Termitidae (Isoptera). ZooKeys, (148), 105-123.

Etienne, R. S., Haegeman, B., Stadler, T., Aze, T., Pearson, P. N., Purvis, A., Phillimore, A. B. (2012). Diversity-dependence brings molecular phylogenies closer to agreement with the fossil record. Proceedings of the Royal Society B: Biological Sciences, 279(1732), 1300-1309.

Evans, T. A., Dawes, T. Z., Ward, P. R., Lo, N. (2011). Ants and termites increase crop yield in a dry climate. Nature Communications, 2(1), 262.

Fordyce, J. A. (2010). Interpreting the y Statistic in Phylogenetic Diversification Rate Studies: A Rate Decrease Does Not Necessarily Indicate an Early Burst. PLOS ONE, 5(7), e11781.

Foster, P. G. (2004). Modeling Compositional Heterogeneity. Systematic Biology, 53(3), 485-495.

Fujioka, T., Chappell, J. (2010). History of Australian aridity: Chronology in the evolution of arid landscapes. Geological Society, London, Special Publications, 346(1), 121-139.

Fujioka, T., Chappell, J., Honda, M., Yatsevich, I., Fifield, K., Fabel, D. (2005). Global cooling initiated stony deserts in central Australia 2-4 Ma, dated by cosmogenic 21Ne-10Be. Geology, 33(12), 993-996.

Fujita, M. K., McGuire, J. A., Donnellan, S. C., Moritz, C. (2010). Diversification and Persistence at the Arid-Monsoonal Interface: Australia-Wide Biogeography of the Bynoe's Gecko (Heteronotia binoei; Gekkonidae). Evolution, 64(8), 2293-2314. 
bioRxiv preprint doi: https://doi.org/10.1101/2021.04.12.439430; this version posted April 22, 2021. The copyright holder for this preprint (which was not certified by peer review) is the author/funder, who has granted bioRxiv a license to display the preprint in perpetuity. It is made available under aCC-BY-NC-ND 4.0 International license.

Gay, F. J. (1955). A new Coptotermes and Ahamitermes (Isoptera) from Australia. Proceedings of the Linnean Society of New South Wales, 79, 177-81.

Gay, F. J. (1968). A contribution to the systematics of the genus Amitermes (Isoptera: Termitidae) in Australia. Australian Journal of Zoology, 16(3), 405-457.

Gillespie, R. G. (2016). Island time and the interplay between ecology and evolution in species diversification. Evolutionary Applications, 9(1), 53-73.

Guzik, M. T., Austin, A. D., Cooper, S. J. B., Harvey, M. S., Humphreys, W. F., Bradford, T., ... Tomlinson, M. (2011). Is the Australian subterranean fauna uniquely diverse? Invertebrate Systematics, 24(5), 407-418.

Hall, R. (2002). Cenozoic geological and plate tectonic evolution of SE Asia and the SW Pacific: Computer-based reconstructions, model and animations. Journal of Asian Earth Sciences, 20(4), 353-431.

Harms, D., Roberts, J. D., Harvey, M. S. (2019). Climate variability impacts on diversification processes in a biodiversity hotspot: A phylogeography of ancient pseudoscorpions in south-western Australia. Zoological Journal of the Linnean Society, 186(4), 934-949.

Hautmann, M. (2020). What is macroevolution? Palaeontology, 63(1), 1-11.

Hill, G. (1922). On some Australian Termites of the Genera Drepanotermes, Hamitermes and Leucotermes. Bulletin of Entomological Research, 12(4), 363-399.

Hill, G. (1942). Termites (Isoptera) from the Australian region (including Australia, New Guinea and islands south of the Equator between $140^{\circ} \mathrm{E}$. Longitude and $170^{\circ} \mathrm{W}$. Longitude. Melbourne, Australia, C.S.I.R.O.

Hill, R.S. (1994). The history of selected Australian taxa. In: History of Australian Vegetation:

Cretaceous to Recent. In RS Hill (Ed.), 390-419. Cambridge University Press, Cambridge, UK.

Ho, S. Y. W., Phillips, M. J. (2009). Accounting for Calibration Uncertainty in Phylogenetic Estimation of Evolutionary Divergence Times. Systematic Biology, 58(3), 367-380.

Holt, J. A., Easey, J. F. (1993). Numbers and biomass of mound-building termites (Isoptera) in a semi-arid tropical woodland near Charters Towers, north Queensland, Australia. Sociobiology, 21(3), 281-286. 
Hughes, L. (2003). Climate change and Australia: Trends, projections and impacts. Austral Ecology, 28(4), 423-443.

Jombart, T. (2008). adegenet: A R package for the multivariate analysis of genetic markers. Bioinformatics, 24(11), 1403-1405.

Jombart, T., Ahmed, I. (2011). adegenet 1.3-1: New tools for the analysis of genome-wide SNP data. Bioinformatics, 27(21), 3070-3071. doi: 10.1093/bioinformatics/btr521

Kearse, M., Moir, R., Wilson, A., Stones-Havas, S., Cheung, M., Sturrock, S., ... Drummond, A. (2012). Geneious Basic: An integrated and extendable desktop software platform for the organization and analysis of sequence data. Bioinformatics, 28(12), 1647-1649.

Krishna, K., Grimaldi, D. (2009). Diverse Rhinotermitidae and Termitidae (Isoptera) in Dominican Amber. American Museum Novitates, 2009(3640), 1-48.

Krishna, K., Grimaldi, D. A., Krishna, V., Engel, M. S. (2013). Treatise on the Isoptera of the World: Termitidae (Part One). Bulletin of the American Museum of Natural History, 2013(377), 973-1495.

Ladiges, Pauline Y., Marks, C. E., Nelson, G. (2011). Biogeography of Nicotiana section Suaveolentes (Solanaceae) reveals geographical tracks in arid Australia. Journal of Biogeography, 38(11), 2066-2077.

Lanfear, R., Calcott, B., Ho, S. Y. W., Guindon, S. (2012). PartitionFinder: Combined Selection of Partitioning Schemes and Substitution Models for Phylogenetic Analyses. Molecular Biology and Evolution, 29(6), 1695-1701.

Lee, T. R. C., Cameron, S. L., Evans, T. A., Ho, S. Y. W., Lo, N. (2015). The origins and radiation of Australian Coptotermes termites: From rainforest to desert dwellers. Molecular Phylogenetics and Evolution, 82, 234-244.

Legendre, F., Condamine, F. L. (2018). When Darwin's Special Difficulty Promotes Diversification in Insects. Systematic Biology, 67(5), 873-887.

Losos, J. B. (2010). Adaptive Radiation, Ecological Opportunity, and Evolutionary Determinism. The American Naturalist, 175(6), 623-639.

Mao, X., Retallack, G. (2019). Late Miocene drying of central Australia. Palaeogeography, 
Palaeoclimatology, Palaeoecology, 514, 292-304.

Matos-Maraví, P., Clouse, R. M., Sarnat, E. M., Economo, E. P., LaPolla, J. S., Borovanska, M., ... Janda, M. (2018). An ant genus-group (Prenolepis) illuminates the biogeography and drivers of insect diversification in the Indo-Pacific. Molecular Phylogenetics and Evolution, 123, 16-25.

Matzke, N. J. (2013). Probabilistic historical biogeography: New models for founder-event speciation, imperfect detection, and fossils allow improved accuracy and model-testing. Frontiers of Biogeography, 5(4).

Matzke, N. J. (2016). Trait-dependent dispersal models for phylogenetic biogeography, in the $R$ package BioGeoBEARS. Integrative and Comparative Biology, 56, E330.

Meng, G., Li, Y., Yang, C., Liu, S. (2019). MitoZ: A toolkit for animal mitochondrial genome assembly, annotation and visualization. Nucleic Acids Research, 47(11), e63-e63.

Miller, L. R. (1984). Invasitermes, a New Genus of Soldierless Termites from Northern Australia (isoptera: Termitidae). Australian Journal of Entomology, 23(1), 33-37.

Minh, B. Q., Schmidt, H. A., Chernomor, O., Schrempf, D., Woodhams, M. D., von Haeseler, A., Lanfear, R. (2020). IQ-TREE 2: New Models and Efficient Methods for Phylogenetic Inference in the Genomic Era. Molecular Biology and Evolution, 37(5), 1530-1534.

Moore, B. R., Höhna, S., May, M. R., Rannala, B., Huelsenbeck, J. P. (2016). Critically evaluating the theory and performance of Bayesian analysis of macroevolutionary mixtures. Proceedings of the National Academy of Sciences, 113(34), 9569-9574.

Morlon, H., Lewitus, E., Condamine, F. L., Manceau, M., Clavel, J., Drury, J. (2016). RPANDA: An R package for macroevolutionary analyses on phylogenetic trees. Methods in Ecology and Evolution, 7(5), 589-597.

Morton, S. R., James, C. D. (1988). The Diversity and Abundance of Lizards in Arid Australia: A New Hypothesis. The American Naturalist, 132(2), 237-256.

Noble, J. C., Müller, W. J., Whitford, W. G., Pfitzner, G. H. (2009). The significance of termites as decomposers in contrasting grassland communities of semi-arid eastern Australia. Journal of Arid Environments, 73(1), 113-119.

Noirot, C., Darlington, J. P. E. C. (2000). Termite Nests: Architecture, Regulation and Defence. In T. 
Abe, D. E. Bignell, M. Higashi (Eds.), Termites: Evolution, Sociality, Symbioses, Ecology (pp. 121-139). Dordrecht: Springer Netherlands.

Nosil, P., Crespi, B. J. (2006). Experimental evidence that predation promotes divergence in adaptive radiation. Proceedings of the National Academy of Sciences, 103(24), 9090-9095.

Nurk S., Bankevich A., Antipov D., Gurevich A., Korobeynikov A., Lapidus A.,Prjibelsky A., Pyshkin A., Sirotkin A., Sirotkin Y., Stepanauskas R., McLean J., Lasken R., Clingenpeel S. R., Woyke T., Tesler G., Alekseyev M. A., Pevzner P. A. (2013) Assembling genomes and mini-metagenomes from highly chimeric reads, $p$ 158-170. In Deng M., Jiang R., Sun F., Zhang X. (ed), Research in computational molecular biology: 17th Annual International Conference, RECOMB 2013, Beijing, China, April 7-10, 2013.Springer, Berlin, Germany.

Oksanen, J., Blanchet, F. G., Friendly, M., Kindt, R., Legendre, P., McGlinn, D., Minchin P. R., O'Hara, R. B., Simpson, G. L., Solymos, P., Henry, M., Stevens, H., Szoecs, E., Wagner, H. (2019) vegan: Community Ecology Package. $\mathrm{R}$ package version 2.5-6. https://CRAN.R-project.org/package=vegan

Owen, C. L., Marshall, D. C., Hill, K. B. R., Simon, C. (2017). How the Aridification of Australia Structured the Biogeography and Influenced the Diversification of a Large Lineage of Australian Cicadas. Systematic Biology, 66(4), 569-589.

Palmer, C. M. (2010). Chronological Changes in Terrestrial Insect Assemblages in the Arid Zone of Australia. Environmental Entomology, 39(6), 1775-1787.

Pepper, M., Fujita, M. K., Moritz, C., Keogh, J. S. (2011). Palaeoclimate change drove diversification among isolated mountain refugia in the Australian arid zone. Molecular Ecology, 20(7), $1529-1545$.

Pincheira-Donoso, D., Harvey, L. P., Ruta, M. (2015). What defines an adaptive radiation? Macroevolutionary diversification dynamics of an exceptionally species-rich continental lizard radiation. BMC Evolutionary Biology, 15(1), 153.

Posada, D., Buckley, T. R. (2004). Model Selection and Model Averaging in Phylogenetics: Advantages of Akaike Information Criterion and Bayesian Approaches Over Likelihood Ratio Tests. Systematic Biology, 53(5), 793-808.

Powney, G. D., Grenyer, R., Orme, C. D. L., Owens, I. P. F., Meiri, S. (2010). Hot, dry and different: Australian lizard richness is unlike that of mammals, amphibians and birds. Global Ecology and Biogeography, 19(3), 386-396. 
Pybus, O. G., Harvey, P. H. (2000). Testing macro-evolutionary models using incomplete molecular phylogenies. Proceedings of the Royal Society of London. Series B: Biological Sciences, 267(1459), 2267-2272.

Rabosky, D. L. (2006). LASER: A Maximum Likelihood Toolkit for Detecting Temporal Shifts in Diversification Rates from Molecular Phylogenies. Evolutionary Bioinformatics, 2, 117693430600200030.

Rabosky, D. L. (2013). Diversity-Dependence, Ecological Speciation, and the Role of Competition in Macroevolution. Annual Review of Ecology, Evolution, and Systematics, 44(1), 481-502.

Rabosky, D. L. (2014). Automatic Detection of Key Innovations, Rate Shifts, and Diversity-Dependence on Phylogenetic Trees. PLOS ONE, 9(2), e89543.

Rabosky, D. L. (2017). Phylogenetic tests for evolutionary innovation: The problematic link between key innovations and exceptional diversification. Philosophical Transactions of the Royal Society B: Biological Sciences, 372(1735), 20160417.

Rabosky, D. L., Donnellan, S. C., Talaba, A. L., Lovette, I. J. (2007). Exceptional among-lineage variation in diversification rates during the radiation of Australia's most diverse vertebrate clade. Proceedings of the Royal Society B: Biological Sciences, 274(1628), 2915-2923.

Rabosky, D. L., Lovette, I. J. (2008). Density-dependent diversification in North American wood warblers. Proceedings of the Royal Society B: Biological Sciences, 275(1649), 2363-2371.

Rambaut, A., Drummond, A. J., Xie, D., Baele, G., Suchard, M. A. (2018). Posterior Summarization in Bayesian Phylogenetics Using Tracer 1.7. Systematic Biology, 67(5), 901-904.

Raven, P. H., Yeates, D. K. (2007). Australian biodiversity: Threats for the present, opportunities for the future. Australian Journal of Entomology, 46(3), 177-187.

Revell, L. J. (2012). phytools: An R package for phylogenetic comparative biology (and other things). Methods in Ecology and Evolution, 3(2), 217-223.

Rix, M. G., Edwards, D. L., Byrne, M., Harvey, M. S., Joseph, L., Roberts, J. D. (2015). Biogeography and speciation of terrestrial fauna in the south-western Australian biodiversity hotspot. Biological Reviews, 90(3), 762-793.

Rozen, S., Skaletsky, H. (2000). Primer3 on the WWW for General Users and for Biologist 
Programmers. In S. Misener S. A. Krawetz (Eds.), Bioinformatics Methods and Protocols (pp. 365-386). Totowa, NJ: Humana Press. doi: 10.1385/1-59259-192-2:365

Toon, A., Crisp, M. D., Gamage, H., Mant, J., Morris, D. C., Schmidt, S., Cook, L. G. (2015). Key innovation or adaptive change? A test of leaf traits using Triodiinae in Australia. Scientific Reports, 5(1), 12398.

Travouillon, K. J., Legendre, S., Archer, M., Hand, S. J. (2009). Palaeoecological analyses of Riversleigh's Oligo-Miocene sites: Implications for Oligo-Miocene climate change in Australia. Palaeogeography, Palaeoclimatology, Palaeoecology, 276(1), 24-37.

Untergasser, A., Cutcutache, I., Koressaar, T., Ye, J., Faircloth, B. C., Remm, M., \& Rozen, S. G. (2012). Primer3-New capabilities and interfaces. Nucleic Acids Research, 40(15), e115-e115.

Watson, J. A. L. (1982). Distribution, biology and speciation in the Australian harvester termites, Drepanotermes (Isoptera: Termitinae). Pages 263-265 in W. R. Barker and P. J. M. Greenslade, eds. Evolution of the flora and fauna of Australia. Peacock Publications, Adelaide, South Australia.

Watson, J. A. L., Gay, F. J. (1991). Isoptera (termites). The Insects of Australia: A Textbook for Students and Research Workers, Vol. 1 (2nd Ed.), 330-347. CSIRO (Division of Entomology). Melbourne University Press, Melbourne.

Watson, J. A. L., Perry, D. H. (1981). The Australian harvester temites of the genus Drepanotermes (Isoptera: Termitinae). Australian Journal of Zoology Supplementary Series, 29(78), 1-153. doi: 10.1071/ajzs078

Wood, D. E., Lu, J., Langmead, B. (2019). Improved metagenomic analysis with Kraken 2. Genome Biology, 20(1), 257. doi: 10.1186/s13059-019-1891-0

Xia, X. (2018). DAMBE7: New and Improved Tools for Data Analysis in Molecular Biology and Evolution. Molecular Biology and Evolution, 35(6), 1550-1552.

Yeates, D. K., Bouchard, P., Monteith, G. B. (2002). Patterns and levels of endemism in the Australian Wet Tropics rainforest: Evidence from flightless insects. Invertebrate Systematics, 16(4), 605-619.

Yeates, D.K., Cassis, G. (2017). Australian insect biogeography: beyond faunal provinces and elements towards processes. In: Ebach, M.C. (Ed.), Handbook of Australasian Biogeography. 
bioRxiv preprint doi: https://doi.org/10.1101/2021.04.12.439430; this version posted April 22, 2021. The copyright holder for this preprint

(which was not certified by peer review) is the author/funder, who has granted bioRxiv a license to display the preprint in perpetuity. It is made available under aCC-BY-NC-ND 4.0 International license.

CRC Press, Boca Raton, Florida, 241-266.

Yoder, J. B., Clancey, E., Roches, S. D., Eastman, J. M., Gentry, L., Godsoe, W., ... Harmon, L. J. (2010). Ecological opportunity and the origin of adaptive radiations. Journal of Evolutionary Biology, 23(8), 1581-1596.

Zachos, J., Pagani, M., Sloan, L., Thomas, E., Billups, K. (2001). Trends, Rhythms, and Aberrations in Global Climate 65 Ma to Present. Science, 292(5517). 